\title{
Diferenças nas propostas de operacionalização do conceito de classe social empregadas em estudos epidemiológicos 1
}

\author{
Differences between proposals for \\ implementation of the social class concept in \\ epidemiological studies 1
}

Jorge José Santos Perei ra Solla 2

\footnotetext{
1 Artigo baseado em dissertação apresentada ao Programa de Mestrado em Saúde Comunitária da Universidade Federal da Bahia.

2 Instituto de Saúde Col etiva, Universidade Federal da Bahia. Rua Padre Feijó, 29/4o andar, Salvador, BA 40110-170, Brasil.
}

\begin{abstract}
A bstract This article compares different proposals for the implementation of the concept of social class and analyzes the al ternatives used in each proposal, considering previous epidemi ological studies on this issue and the potential of such a concept as a central category in studies on social determination in the health/disease process. Seven basic differences were identified, pertaining to the following aspects: class structure; research objective; the social class concept as a reference; the decision as to which individual has his/her occupational activity taken as defining the family's social class; the class status of the unemployed, housewives, and the retired; class status of students; and criteria for distinguishing between the "bourgeoisi e", "petty bourgeoi si e", "new petty bourgeoisie", and "prol etariat" and whether there is a specific flow in certain population groups. Given the observed differences and underlying theoretical models, this study discusses problems related to the fact that the use of a specific concept of social class can have various implementation models.
\end{abstract}

Key words Social Class; Social Stratification; Epidemiology

Resumo Diante do emprego em estudos epi demi ológi cos de diversas propostas de operaci onalização do concei to de classe social, e da demonstração em várias investi gações das potenciali dades da utilização deste concei to enquanto categoria central no estudo da determi nação social do processo saúde-doença, o presente artigo compara propostas diferentes, realizando uma contraposição das alternati vas empregadas em cada uma delas. São identi fi cadas sete di ferenças básicas entre as propostas estudadas, dizendo respeito a: estrutura de classe, objetivo da investigação, conceito de classe social tomado como referência, decisão acerca de qual indivíduo terá sua inserção produtiva tomada como definidora da classe social da família, situação de classe dos desempregados, donas de casa e aposentados, situação de estudantes, e, por último, critério para diferenciação entre Burguesia e Pequena Burguesia, entre Nova Pequena Burguesia e Proletariado e a existência defluxo específico ou não para certos grupos populacionais. A partir das diferenças observadas e dos model os teóri cos subj acentes são levantados e discuti dos problemas relacionados ao fato de que a utilização de um mesmo conceito de classe social podelevar a modelos de operacionalização distintos.

Palavras-chave Classe Social; Operacionalização; Estratificação Social; Epidemiologia 


\section{Introdução}

Várias investigações epidemiológicas têm demonstrado as potencialidades da utilização do conceito de classe social como uma categoria chave para o estudo da determinação social do processo saúde-doença.

A magnitude das diferenças identificadas entre as classes sociais no tocante aos estudos da morbi-mortalidade e do acesso aos serviços de saúde, a consistência observada nos resultados dos diversos estudos realizados e a coerência com o conhecimento científico acumulado neste campo de investigação, evidenciam a importância do emprego do conceito de classe social e de sua operacionalização, para reforçar o instrumental metodológico, articulando o processo saúde-doença com as relações sociais de produção através da inserção de classe dos indivíduos investigados (Almeida et al., 1992; Barros, 1986; Bronfman \& Tuirán, 1984; Bronfman et al., 1988; Forster \& Yazlle-Rocha, 1991; Monteiro, 1988; Silva et al., 1991; Solla, 1992; Victora et al., 1989).

Victora et al. (1990), estudando o emprego da inserção de classe nas investigações epidemiológicas, apontam como principal vantagem o fato de que tal categoria tem um potencial explicativo sobre a realidade investigada, ao determinar um conjunto de variáveis sócioeconômicas, como renda e grau de escolaridade. Também Bronfman \& Tuirán (1984) tecem comentários sobre o papel destas variáveis: “A relação entre a posi ção de classe dos indi víduos e seu comportamento demográfico está medi ada por um complexo conjunto de fatores (...) que, em seu conjunto, dão forma às condições materiais de existência, não explicam individualmentenem a gênese nem o desenvol vimento da desigualdadesocial e, portanto, tampouco dão conta dos processos saúde-enfermidademorte que ocorrem em uma sociedade".

Algumas propostas de operacionalização do conceito de classe social têm sido empregadas em investigações epidemiológicas. Neste trabalho destacamos as de Barros (1986), Bronfman \& Tuirán (1984) e Bronfman et al. (1988), e a desenvolvida por Wright (1981, 1985), em estudos sociológicos, utilizada em um grande inquérito multicêntrico. Estas propostas divergem em vários aspectos, sendo nosso objetivo apresentá-las de forma esquemática, buscando uma contraposição das alternativas empregadas em cada uma delas.

\section{O conceito}

As propostas de operacionalização analisadas partem do conceito de classe social elaborado por Lenin (1980). Segundo Bronfman \& Tuirán (1984), este conceito apresenta as seguintes dimensões:

1) Lugar que ocupam (os indivíduos) em um sistema de produção social determinado - posição em que os indivíduos se inserem dentro das relações de exploração.

2) Relações em que se encontram os indivíduos com respeito aos meios de produção propriedade ou não dos meios de produção e de trabalho.

3) Papel que desempenham os indivíduos na organização social do trabalho - formas de controle sobre o processo de trabal ho e de produção. 4) Modo e proporção em que os indivíduos recebem a parte da riqueza social de que dispõem - depende em última instância das dimensões anteriores, não sendo mais que seu efeito.

Para definição da inserção de classe do indivíduo nestas propostas, o critério inicial e fundamental é a rel ação com os mei os de produção, sendo as demais variáveis utilizadas a partir deste ponto. Para cada dimensão encontrada neste conceito de classe social, são relacionadas variáveis e indicadores (Bronfman \& Tuirán, 1984).

\section{As diferenças}

As sete principais diferenças existentes entre as propostas de operacionalização do conceito de classe social estudadas são apresentadas esquematicamente na Tabela 1.

A primeira é quanto às estruturas de classe empregadas nas propostas apresentadas, que diferem em relação à definição de três conjuntos de classes:

1) Enquanto Bronfman \&Tuirán (1984) e Bronfman et al. (1988) empregaram a distinção entre Burguesia e Nova Pequena Burguesia, Barros (1986) separa a Burguesia em dois segmentos (Empresarial e Gerencial), e Wright (1985) emprega Burguesia e Situação contraditória entre Burguesia e Proletariado. Estas diferenças resultam em distintas formas de classificar os técnicos, diretores, gerentes (tecnoburocracia) que se encontram inseridos na Burguesia Gerencial (Barros, 1986), na Nova Pequena Burguesia (Bronfman \& Tuirán, 1984; Bronfman et al., 1988) e na Situação contraditória de classe entre a Burguesia e o Proletariado (Wright, 1985). 
2) O Proletariado em Bronfman \& Tuirán (1984) e em Bronfman et al. (1988) foi diferenciado em dois tipos (Típico e Atípico), Barros (1986) e Wright (1985) não fizeram tal distinção. Barros (1986) apontou a necessidade de discriminar os trabalhadores diretamente produtivos, no entanto a ausência de informações suficientes e de um esquema mais definido quando do momento da coleta de dados não permitiram avançar neste aspecto.

3) Os indivíduos que realizam atividade produtiva predominantemente não-assalariada, em geral instável, não possuindo meios de produção próprios, foram classificados no trabaIho de Bronfman \& Tuirán (1984) como Força de Trabalho "Livre” distinguindo entre "assalariada" e "não-assalariada". Já em Barros (1986) e em Bronfman et al. (1988) a denominação passou a ser Subproletariado, sendo que este último estudo o diferencia entre "assalariados" e “não-assalariados”. Por último, Wright (1985) substitui o emprego da Força de Trabalho “Livre" ou do Subproletariado pela existência de uma Situação contraditória de classe entre o Proletariado e a Pequena Burguesia.

Um segundo aspecto aponta que, com exceção do trabalho de Wright (1985), que teve como objetivo identificar os grupos organizados que serão os atores principais na ação coletiva e no conflito social, todos os outros estudados se propõem a investigar o porquê de os indivíduos diferirem em relação ao processo saúde-doença e ao acesso a serviços de saúde e medicamentos.

Em terceiro lugar, todas as propostas partem do conceito de classe social elaborado por Lenin, exceto Wright (1985), que toma como referencial inicial os trabalhos de Poulantzas; cabendo ressal tar que Poulantzas (1975) assume em suas obras como ponto de partida em suas elaborações a conceituação de classe definida por Lenin (1980).

Em quarto lugar, a definição de classe social é feita por Barros (1986) a partir da inserção produtiva do "chefe" da família; em Bronfman et al. (1988), pela inserção na produção do componente da família que recebia a maior renda; e em Bronfman \& Tuirán (1984) a inserção de classe da entrevistada era sempre definida a partir da atividade produtiva do homem, que poderia ser o cônjuge (se casada), o último marido ou companheiro (se viúva ou separada), ou o pai (se nunca esteve casada).

Um quinto aspecto trata da situação de classe dos desempregados, donas-de-casa e aposentados que fossem "chefes" de família. Estes eram classificados como Subproletariado por Barros (1986) (exceto famílias com chefes aposentados, as quais foram excluídas, devido à inexistência de informação sobre história ocupacional pregressa), tinham sua inserção definida pelo grupo familiar na proposta de Bronfman \& Tuirán (1984) e eram excluídos da classificação no estudo de Bronfman et al. (1988). Para Wright (1985) os permanentemente desempregados geral mente são considerados como Lupem-Proletariado, um segmento marginalizado da classe operária, os aposentados têm sua inserção de classe definida pela sua atividade produtiva no passado (Trajetória de classe) e as donas-de-casa, a partir da situação de classe do marido, ou seja, a forma como a família está inserida nas relações capitalistas de produção.

Em sexto lugar, em relação aos estudantes, Bronfman et al. (1988) consideram que devem ser enquadrados de acordo com a inserção de classe do responsável pelo seu sustento, e Wright (1985) trabalha com a inserção futura dos estudantes, quando terminarem seus estudos, empregando o conceito de "Trajetória de Classe".

Uma sétima questão diz respeito à diferenciação entre Burguesia e Pequena Burguesia, entre Nova Pequena Burguesia e Proletariado entre os assalariados, e a existência de fluxo específico ou não para certos grupos profissionais:

- Bronfman \& Tuirán (1984) e Wright (1985) tomam como critério o número de empregados para demarcar a Burguesia da Pequena Burguesia. Enquanto Wright (1985) não explicita um ponto de corte, Bronfman \& Tuirán (1984) consideram Burguesia quando apresentar um mínimo de empregados igual ou superior a 5, e Pequena Burguesia quando este número for igual ou inferior a 4. Em Barros (1986) e em Bronfman et al. (1988) é acrescentada outra variável: a renda, sendo que Barros (1986) usa um ponto de corte para a Burguesia igual a ou maior do que nove salários mínimos e trabalha com renda ou número de empregados; já Bronfman et al. (1988) usam renda e número de empregados e o limite de renda para a Pequena Burguesia é estabelecido em valor menor ou igual a 15 salários mínimos.

O Proletariado Atípico empregado por Bronfman \& Tuirán (1984) e por Bronfman et al . (1988) corresponde a indivíduos assalariados no setor terciário (sem qualificação e sem cargo de direção ou chefia) e aqueles que estão inseridos indiretamente na produção também sem possuírem cargo de direção nem apresentando qualificação. Esta última variável corresponde em Bronfman et al. (1988) à presença de “Formação Universitária” para a atividade pro- 
Tabela 1

Diferenças entre propostas de operacionalização do conceito de classe social

\begin{tabular}{|c|c|c|c|c|}
\hline & $\begin{array}{l}\text { Barros } \\
(1986)\end{array}$ & $\begin{array}{l}\text { Bronfman \& Tuirán } \\
\text { (1984) }\end{array}$ & $\begin{array}{l}\text { Bronfman et al. } \\
(1988)\end{array}$ & $\begin{array}{l}\text { Wright } \\
(1985)\end{array}$ \\
\hline \multirow[t]{8}{*}{ Estrutura de classes } & Burguesia empresarial & Burguesia & Burguesia & Burguesia \\
\hline & Burguesia gerencial & $\begin{array}{l}\text { Nova pequena } \\
\text { burguesia }\end{array}$ & $\begin{array}{l}\text { Nova pequena } \\
\text { burguesia }\end{array}$ & $\begin{array}{l}\text { Situação contraditória: } \\
\text { (Burguesia x Proletariado) }\end{array}$ \\
\hline & & & & $\begin{array}{l}\text { Situação contraditória: } \\
\text { (Burguesia x Pequena burguesia) }\end{array}$ \\
\hline & Pequena burguesia & Pequena burguesia & Pequena burguesia & Pequena burguesia \\
\hline & Proletariado & $\begin{array}{l}\text { Proletariado } \\
\text { típico } \\
\text { atípico }\end{array}$ & $\begin{array}{l}\text { Proletariado } \\
\text { típico } \\
\text { atípico }\end{array}$ & Proletariado \\
\hline & Subproletariado & $\begin{array}{l}\text { Força de } \\
\text { trabalho "livre" }\end{array}$ & Subproletariado & $\begin{array}{l}\text { Situação contraditória: } \\
\text { (Proletariado x Pequena burguesia) }\end{array}$ \\
\hline & & Assalariado & Assalariado & \\
\hline & & $\mathrm{N}$ ão-assalariado & $\mathrm{N}$ ão-assalariado & \\
\hline Propósitos da investigação & $\begin{array}{l}\text { Por que indivíduos } \\
\text { diferem em termos } \\
\text { de condições de } \\
\text { saúde, consumo de } \\
\text { serviços de saúde e } \\
\text { uso de medicamentos }\end{array}$ & $\begin{array}{l}\text { Por que indivíduos } \\
\text { diferem em termos } \\
\text { de condições de } \\
\text { saúde, consumo de } \\
\text { serviços de saúde e } \\
\text { uso de medicamentos }\end{array}$ & $\begin{array}{l}\text { Por que indivíduos } \\
\text { diferem em termos } \\
\text { de condições de } \\
\text { saúde, consumo de } \\
\text { serviços de saúde e } \\
\text { uso de medicamentos }\end{array}$ & $\begin{array}{l}\text { Que grupos } \\
\text { organizados serão } \\
\text { os atores principais } \\
\text { na ação coletiva e no } \\
\text { conflito social }\end{array}$ \\
\hline $\begin{array}{l}\text { Conceito de classe social } \\
\text { Define a classe social pela }\end{array}$ & Lenin & Lenin & Lenin & Poulantzas (Lenin) \\
\hline inserção na produção do: & "Chefe" da família & $\begin{array}{l}\text { a) cônjuge } \\
\text { b) último marido } \\
\text { ou companheiro } \\
\text { c) pai (inserção de } \\
\text { classe da mulher) }\end{array}$ & $\begin{array}{l}\text { Componente da } \\
\text { família que recebia } \\
\text { a maior renda }\end{array}$ & - \\
\hline Situação dos desempregados & Subproletariado & $\begin{array}{l}\text { Inserção dos } \\
\text { "inativos" definida } \\
\text { pelo grupo familiar }\end{array}$ & Não-classificável & $\begin{array}{l}\text { Segmento marginalizado } \\
\text { da classe operária - } \\
\text { "Lupem Proletariado" }\end{array}$ \\
\hline Situação das donas-de-casa & Subproletariado & $\begin{array}{l}\text { Inserção dos } \\
\text { "inativos" definida } \\
\text { pelo grupo familiar }\end{array}$ & Não-classificável & $\begin{array}{l}\text { Situação de classe } \\
\text { do marido (família) }\end{array}$ \\
\hline
\end{tabular}

dutiva que o indivíduo desempenha. Para Wright (1985) o que define a situação contraditória de classe entre Burguesia e Proletariado é o grau de controle imediato sobre suas condições de trabalho, sobre o que produzem, sendo técnicos e profissionais altamente qualificados.

A respeito dos assalariados na construção civil, observa-se que Barros (1986) coloca todo este grupo no Subproletariado (não dispondo de possibilidade para discriminar os peões dos demais trabal hadores da construção civil, de- vido à maneira como haviam sido coletados e codificados os dados acerca da ocupação, e considerando que na construção civil predominam trabalhadores sem qualificação, Barros (1986) utilizou esta opção), Bronfman \& Tuirán (1984) os insere no Proletariado Típico eWright (1985) no Proletariado (não diferenciando entre Típico e Atípico). Já o trabalho de Bronfman et al. (1988) criou um fluxo específico para este grupo separando de acordo com o conhecimento do ofício entre o Subproletariado (serventes) e o Proletariado Típico (oficiais). Tal 
Diferenças entre propostas de operacionalização do conceito de classe social.

\begin{tabular}{|c|c|c|c|c|}
\hline & $\begin{array}{l}\text { Barros } \\
(1986)\end{array}$ & $\begin{array}{l}\text { Bronfman \& Tuirán } \\
(1984)\end{array}$ & $\begin{array}{l}\text { Bronfman et al. } \\
\text { (1988) }\end{array}$ & $\begin{array}{l}\text { Wright } \\
(1985)\end{array}$ \\
\hline Situação dos aposentados & $\mathrm{N}$ ão incluídos & $\begin{array}{l}\text { Inserção dos } \\
\text { “inativos” definida } \\
\text { pelo grupo familiar }\end{array}$ & Não-classificável & $\begin{array}{l}\text { Inserção passada } \\
\text { "Trajetória de classe" }\end{array}$ \\
\hline Situação dos estudantes & - & $\begin{array}{l}\text { Inserção dos } \\
\text { “inativos" definida } \\
\text { pelo grupo familiar }\end{array}$ & $\begin{array}{l}\text { Inserção (classe) } \\
\text { do responsável } \\
\text { por seu sustento }\end{array}$ & $\begin{array}{l}\text { Inserção futura } \\
\text { "Trajetória de classe" }\end{array}$ \\
\hline $\begin{array}{l}\text { Diferenças entre burguesia } \\
\text { e pequena burguesia }\end{array}$ & $\begin{array}{l}\text { Renda } \\
(<9 \text { s.m. / > } 9 \text { s.m.) } \\
\text { ou Número de } \\
\text { empregados } \\
\text { (até } 4 \text { / } 5 \text { ou }+ \text { ) }\end{array}$ & $\begin{array}{l}\text { Número de } \\
\text { empregados } \\
\text { (até } 4 \text { / } 5 \text { ou }+ \text { ) }\end{array}$ & $\begin{array}{l}\text { Renda } \\
\text { (<15 s.m. / > } 15 \text { s.m.) } \\
\text { e Número de } \\
\text { empregados } \\
\text { (até } 4 \text { / } 5 \text { ou +) }\end{array}$ & Número de empregados \\
\hline $\begin{array}{l}\text { Inserção de técnicos, } \\
\text { diretores e gerentes } \\
\text { (tecnoburocracia) }\end{array}$ & Burguesia gerencial & $\begin{array}{l}\text { Nova pequena } \\
\text { burguesia }\end{array}$ & $\begin{array}{l}\text { Nova pequena } \\
\text { burguesia }\end{array}$ & $\begin{array}{l}\text { Situação contraditória: } \\
\text { (Burguesia x Proletariado) }\end{array}$ \\
\hline $\begin{array}{l}\text { Assalariados do } \\
\text { setor terciário } \\
\text { (sem qualificação/chefia) }\end{array}$ & Proletariado & Proletariado atípico & Proletariado atípico & Proletariado \\
\hline $\begin{array}{l}\text { Diferenças entre nova } \\
\text { pequena burguesia e } \\
\text { proletariado entre os } \\
\text { assalariados }\end{array}$ & $\begin{array}{l}\text { Burguesia gerencial } \\
\text { (técnicos, diretores } \\
\text { e profissionais) } \\
\text { * controle do } \\
\text { processo econômico }\end{array}$ & $\begin{array}{l}\text { Responsabilidade } \\
\text { no serviço } \\
\text { (alta/baixa) }\end{array}$ & $\begin{array}{l}\text { Formação } \\
\text { universitária } \\
\text { (sim/não) } \\
\text { Tipo de função } \\
\text { (diretiva/não-diretiva) }\end{array}$ & $\begin{array}{l}\text { Controle imediato } \\
\text { sobre suas condições } \\
\text { de trabalho e sobre o } \\
\text { que produzem: } \\
\text { profissionais altamente } \\
\text { qualificados }\end{array}$ \\
\hline $\begin{array}{l}\text { Assalariados na } \\
\text { construção civil }\end{array}$ & Subproletariado & Proletariado Típico & $\begin{array}{l}\text { Fluxo específico: } \\
\text { * serventes }= \\
\text { Subproletariado } \\
\text { * oficiais }= \\
\text { Proletariado Típico }\end{array}$ & Proletariado \\
\hline $\begin{array}{l}\text { Atividade } \\
\text { não-assalariada, } \\
\text { em geral instável }\end{array}$ & Subproletariado & $\begin{array}{l}\text { Força de trabalho } \\
\text { "livre" }\end{array}$ & Subproletariado & Proletariado \\
\hline
\end{tabular}

s.m.: Salário mínimo

decisão foi tomada devido à alta rotatividade desta categoria ocupacional (serventes).

\section{Outros estudos}

Alguns estudos epidemiológicos têm utilizado, muitas vezes de forma adaptada, as propostas acima apresentadas:

Monteiro (1988), em São Paulo (SP), e Victora et al. (1989), em Pelotas (RS), investigando as condições de saúde de crianças, emprega- ram a proposta desenvolvida pelo trabalho de Bronfman et al. (1988);

Silva et al. (1991), estudando a determinação social do Baixo Peso ao Nascer, e Almeida et al. (1992), relacionando mortalidade infantil com classe social e peso ao nascer, ambos estudos desenvolvidos em Ribeirão Preto (São Paulo), utilizaram a proposta de Barros (1986);

Forster \&Yazlle-Rocha (1991), analisando a distribuição das hospitalizações de acordo com a classe social em Ribeirão Preto (SP), empregaram a proposta de Barros (1986), reali- 
zando uma alteração: retirando do Sub-Proletariado o grupo constituído pelas donas-de-casa, afastados do trabalho e aposentados, constituindo um grupo à parte ("sem classe").

Mota, Solla, Aquino e colaboradores, empregando no "Projeto Morbi-Mortalidade Materno-Infantil em Salvador (Bahia), 1987/ 88" (UFBA, 1986) um esquema de operacionalização, desenvolvido a partir da proposta de Bronfman et al. (1988), empreenderam as seguintes modificações: a) estabelecendo a classe social pela inserção produtiva do "chefe" da família - definido pela própria família; b) criando um “Grupo Fora da População Economicamente Ativa" (Fora da P.E.A.), onde ficam enquadrados os casos em que o "chefe" da família era desempregado, dona-de-casa, aposentado ou estudante; c) diferenciando a Burguesia da Pequena Burguesia apenas pelo critério do número de empregados (até 4/5 ou mais), sem utilizar o critério de renda; d) utilizando a denominação Força de Trabal ho "Livre", no lugar de Subproletariado, e não fazendo distinção nesta classe social entre assalariados e não-assalariados. Com estas modificações o esquema de operacionalização foi empregado em diversas análises a respeito da morbi-mortalidade e do acesso a serviços de saúde em uma coorte de crianças nascidas vivas em Salvador (BA) e acompanhadas durante o primeiro ano de vida (Solla, 1992).

\section{Os problemas}

A partir das diferenças observadas e dos modelos teóricos subjacentes a estas propostas podemos identificar problemas relacionados ao fato de que a utilização de um mesmo conceito de classe social pode levar a model os de operacionalização distintos devido a diferentes interpretações a respeito de diversos aspectos teórico-conceituais.

São vários os pontos que poderiam ser levantados como fundamentais nesta questão; contudo, três deles assumem aspecto primordial:

a) Sobre a contraposição entre os conceitos de "classe em si" e de "classe para si", ou seja, "Plano exclusivamente econômico" versus "Plano Econômico - campo político/jurídico/ideológico"

Com relação a este primeiro aspecto, os autores do marxismo clássico e outros que seguiram por caminhos semel hantes concebem o conceito de classe social assumindo duas dimensões distintas: a "classe em si" - efeito da matriz econômica e sua existência objetiva, e a "classe para si" - sujeito histórico construído através da organização e consciência de seus membros.

A partir deste raciocínio, desenvolveram-se duas tendências principais: a primeira considera que a esfera econômica por si só delimita a constituição das classes sociais, e a segunda, apesar de discordar da anterior, assume que na investigação empírica o plano econômico é o único passível de ser capturado através do arsenal metodológico existente. Esta última linha é a hegemônica nos estudos epidemiológicos que buscam empregar a classe social em seu instrumental.

No entanto, cabe ressaltar o ponto de vista de outros autores que divergem de tal construção. Poulantzas (1975) aponta o fato de que a divisão social do trabalho e os lugares ocupados pelos indivíduos em sua inserção produtiva compreendem relações políticas e ideológicas, representando um conjunto de práticas sociais, não dizendo respeito, portanto, apenas à esfera econômica, e sim à articulação das instâncias econômica, política e ideológica. Isto não significa que uma classe social não possa assumir posições distintas de seus "interesses objetivos".

O autor considera que se reduzirmos a determinação estrutural de classe à posição de classe estaremos deixando de lado a determinação obj etiva dos lugares das cl asses sociais e assumindo em troca uma ideologia relacional de movimentos sociais: “Pode-se bem observar que as relações ideológicas e políticas, isto é, os lugares de dominação-subordinação política e ideológica já se referem a uma determinação estrutural de classe; não se trata, pois, de um lugar objetivo que só diria respeito ao lugar econômico nas relações de produção, só se encontrando os elementos políticos e ideológicos nas posições de classe. Não se trata, segundo um antigo equívoco, de uma estrutura econômica que designa, sozinha, de um lado os lugares, e de outro uma luta de classes que se estende ao domínio político e ideológico: tal equívoco toma atualmente com freqüência a forma de uma distinção entre situação (econômica) de classe de um lado, e posições político-ideológicas de classe, expressando-se todas essas lutas pelas posi ções de classe na conjuntura" (Poulantzas, 1975).

Wright (1981; 1985), apesar de avançar em várias formulações a partir dos pontos de vista de Poulantzas, assume também que a divisão social do trabalho é definidora das classes sociais e das "situações contraditórias de classe". 
Para outros autores a constituição das classes sociais é precedida pela luta de classes que conforma as práticas sociais definidoras destas (Guimarães, 1988). Assim, Przeworsky (1989) considera que as classes são constituídas pelas lutas travadas, as quais não são definidas exclusivamente nas relações de produção. Para ele as classes não têm sua constituição dada por posições objetivas. Tais posições implicam apenas limites para a luta política.

Segundo este autor, as classes são formadas no decorrer das lutas, estruturadas a partir das condições econômicas, políticas e ideológicas sob as quais ocorrem; “(...) essas condi ções objetivas (...) moldam a prática de movimentos que procuram organizar os operários em uma classe. (...) As classes não são um elemento anteri or à história das lutas concretas. Como afirmou Marx e Gramsci não se cansou de repetir, é na esfera da ideologia que as pessoas tomam ciência das relações sociais. Aquilo em que passam a acreditar e o que fazem é efeito de um longo processo de persuasão e organização por forças políticas e ideológi cas engajadas em numerosas lutas pel a real i zação de seus obj etivos. (...) As classes não antecederam a prática política e ideológica. Qualquer defini ção das pessoas como operári os (...) é necessariamente inerente à prática de forças políticas engajadas em lutas para manter ou alterar de várias manei ras as relações sociais existentes. As classes são organizadas e desorganizadas em conseqüência de lutas contínuas" (Przeworsky, 1989).

Estas diferentes posições vão necessariamente ter implicações sobre os processos de investigação, onde se refletem em três visões distintas:

- Concorda com a existência de duas dimensões distintas do conceito de classe, aceitando a necessidade e a viabilidade de operacionalizar tal conceito para aplicá-lo na investigação empírica; no entanto, este processo só alcançaria a dimensão meramente econômica das classes, deixando à margem os reflexos das dimensões política/ jurídica/ ideológica. Esta ótica é compartilhada pelas investigações epidemiológicas que operacionalizaram o conceito de classe social (Barros, 1986; Bronfman \& Tuirán, 1984; Bronfman et al., 1988).

- Concebe as classes sociais como sendo formadas pelas lutas travadas, como efeito destas, sendo um processo contínuo, onde as classes se organizam, desorganizam e se reorganizam; sendo, portanto, uma relação - nem os ocupantes de lugares nas relações de produção, nem o conjunto de atores na ação coletiva -, a investigação deve dirigir-se para a identificação dos determinantes e das conseqüências destes em lutas concretas, não cabendo demandas de construção de categorias correspondentes às classes sociais definidas a partir da inserção produtiva dos indivíduos estudados. Tal concepção não permite a construção de modelos para a análise epidemiológica onde a determinação dos padrões de vida e de consumo seja investigada a partir da maneira como os indivíduos estão inseridos nas relações de produção estabelecidas.

- Interpreta as classes sociais como efeito da articulação das estruturas econômicas, ideológicas, jurídicas e políticas, ocupando lugares objetivos nas relações de produção, lugares de dominação-subordinação política e ideológica. O emprego deste conceito, construído com base na inserção no aparato produtivo, relações sociais, relações técnicas e relações de distribuição operacionalizadas para instrumentar uma investigação, teria justificativa como um empreendimento para a produção de conhecimento sobre a realidade social. Esta tarefa demanda a compreensão dos processos sociais subjacentes às relações de classe na formação econômico-social concreta estudada. Tal abordagem pode ser encontrada nas investigações desenvolvidas por Wright (1981; 1985) e, ao nosso ver, permite uma melhor compreensão das determinações relacionadas ao processo saúde-doença e ao acesso aos serviços de saúde na sociedade capitalista.

b) A respeito de concepções mais restritivas ou menos restritivas de classe operária (Proletariado) e sobre o crescimento do conjunto de assalariados não inseridos diretamente na produção, devido principalmente ao desenvolvimento do setor terciário da economia.

Para Wright (1981), devido ao fato de as classes não serem apenas abstrações analíticas na teoria marxista, e sim forças sociais, a forma como são conceituadas e as categorias de posições sociais que são atribuídas a cada classe têm importância fundamental: "Todos os marxistas concordam em que os trabal hadores manuais diretamente empenhados na produção de mercadorias concretas para o capital privado pertencem à classe operária. (...) Tal consenso não se verifica quanto a qualquer outra categoria deassalariados. Alguns marxistas (entre eles Poulantzas) argumentaram que só os trabalhadores manuais produtivos devem ser consi derados membros da classe operária. Outros opinam que a classe operária inclui também empregados deescritório denível inferior e da rotina burocrática [por exemplo, Al Szymanski]. Outros ainda são de parecer que vi rtualmente todos os assalariados devem ser considerados parte da classe ope- 
rária [por exemplo, Francesca Freedman]. (...) Mas as classes não são apenas abstrações analíti cas na teoria marxista; são reais forças sociais etêm reais conseqüências. Importa muito para a nossa compreensão da luta declasses e da mudança social o modo preciso como as classes são concei tuadas e que categorias de posições sociais são atribuídas a tais e quais classes."

Enquanto Poulantzas (1975) delimita o proletariado como sendo formado por apenas aqueles trabalhadores manuais não-supervisores e que produzem mais-valia diretamente, Wright $(1981 ; 1985)$ emprega um critério mais amplo: todos os assalariados que ocupam posições que excluam toda forma de controle sobre o capital monetário, sobre o capital físico e sobrea força de trabalho. Tal opção, como pode ser evidenciado, pode também estar diretamente relacionada aos objetivos da análise.

As concepções acerca das inserções informais instáveis e/ ou autônomas no mercado de trabalho no interior da sociedade capitalista irão também determinar alterações na composição da estrutura de classes sociais empregada na investigação empírica.

Tais divergências vão repercutir sobre as propostas de operacionalização do conceito de classe social sob a forma de três questões básicas:

- composição do proletariado (mais ampla ou mais restrita);

- divisão ou não do proletariado em duas frações: o Proletariado Típico e o Proletariado Atípico;

- inclusão dos trabalhadores assalariados ou não-assalariados que possuem uma inserção instável, sem propriedade dos meios de produção, no Proletariado ou na Força de Trabalho “Livre"/ Subproletariado.

c) Sobre o grande crescimento da complexidade das relações sociais com a evolução do capitalismo, decorrente das transformações estruturais ocorridas - inserção de técnicos, diretores e gerentes.

O enorme crescimento da complexidade existente no interior das relações sociais, decorrente das transformações estruturais desenvolvidas na evolução histórica do capitalismo, demandou novas formulações a respeito da inserção de determinados segmentos que passaram a assumir papel relevante dentro da sociedade atual (Therborn, 1989; Wright, 1981; 1985). A partir de tal demanda foram elaboradas abordagens diferenciadas a respeito desta questão.

Para Wright $(1981 ; 1985)$ tais mudanças poderiam ser sintetizadas em processos referen- tes à perda de controle sobre o processo de trabalho por parte dos produtores diretos, ao surgimento de novas e mais complexas hierarquias de autoridade dentro das empresas, à diferenciação entre propriedade econômica e posse e entre propriedade legal formal e propriedade econômica real.

Para o processo de operacionalização do conceito de classe social tais pontos de vista vão se expressar nas propostas estudadas em três alternativas:

- Divisão da Burguesia em duas frações: a Burguesia Empresarial ea Burguesia Gerencial; - Existência da Nova Pequena Burguesia, reunindo o contingente de assalariados com alta qualificação técnica e/ ou que assumiram a direção do processo de produção e o controle sobre a força de trabalho assalariada;

- Identificação de "Situações Contraditórias de Classe" entre a Burguesia e o Proletariado.

\section{Comentários finais}

Ressaltamos que, neste momento do desenvolvimento metodológico nos estudos epidemiológicos, discutir a utilização do conceito de classe social em tais estudos, comparando as diversas propostas de operacionalização empregadas, além de demandar um aprofundamento teórico-conceitual, passa necessariamente pela identificação das potencialidades deste arsenal metodológico, assim como dos problemase limites enfrentados em seu emprego, buscando aperfeiçoar o tratamento dispensado a este instrumental pelas investigações nesta área do conhecimento.

Entre diversos aspectos que também deveriam ter sido abordados neste trabalho encontra-se a necessidade de adaptação da proposta de operacionalização a ser empregada levando em consideração as particularidades da formação sócio-econômica estudada (Solla, 1996).

Em nosso campo de investigação, vários esforços vêm sendo desenvolvidos para superar estes obstáculos (Almeida Filho, 1989; Arouca, 1976; Barros, 1986; Breilh, 1987; 1989a; 1989b; 1990; 1991; Breilh \& Granda, 1985; 1986; Bronfman \& Tuirán, 1984; Bronfman et al., 1988; Dunningham, 1988; Solla, 1990; 1992; Victora et al., 1990) e coadunando com as conclusões de Bronfman et al. (1988), consideramos fundamental este processo, pois, ao se superarem as dificuldades no plano teórico-conceitual e se al cançar um desenvolvimento dos modelos de operacionalização, “(...) poder-se-á captar a situação de classe dos grupos sociais e a forma em que esta afeta a saúde dos indivíduos que a 
compartem em determinada formação econômico-social".

Neste processo a Epidemiologia pode avançar no sentido de buscar a superação dos entraves existentes que dificultam a abordagem de seu objeto a partir de um ponto de vista mais global e completo.

\section{Referências}

ALMEIDA, L.; BARBIERI, M.; GOMES, V.; REIS, P M. dos; CHIARATTI, T M.; VASCONCELOS, V. \& BETTIOL, H., 1992. Peso ao nascer, classe social e mortalidade infantil em Ribeirão Preto (SP). Cadernos de Saúde Pública, 8:190-198.

ALMEIDA FILHO, N. de, 1989. Epidemiologia Sem Números: uma Introdução Crítica à Ciência Epidemiológica. Rio de Janeiro: Campus.

AROUCA, A. S. da S., 1976. A história natural das doenças. Saúdeem Debate, 1:15-19.

BARROS, M. B. de A., 1986. A utilização do conceito de classe social nos estudos dos perfis epidemiológicos: uma proposta. Revista de Saúde Pública, 20:269-73.

BREILH, J., 1987. La epidemiología entre fuegos. In: Taller Latinoamericano de Medicina Social, (J. Breilh, org.), pp. 35-59. Medellin: Associação Latinoamericana de Medicina

BREILH, J., 1989a. El marxismo en la defensa y transformación de la vida. Breves reflexiones acerca de sus aportes teórico-prácticos en el campo de la salud. In: XI Conferencia Internacional sobrelas Ciencias Sociales y Medicina. Países Bajos: CEAS. (mimeo.)

BREILH, J., 1989b. La Reprodución Social y el Proceso Epidemiológico. (mimeo.)

BREILH, J., 1990. La Epidemiología Crítica Latinoamericana. Quito: Proyeto ALAMES-OPS.

BREILH, J., 1991. Epidemiologia, Economia, Política e Saúde. São Paulo: UNESP-HUCITEC.

BREILH, J. \& GRANDA, E., 1985. Os novos rumos da Epidemiologia. In: As Ciências Sociais em Saúde na América Latina, (Nunes, E. D., org.), pp. 241-253. Brasília: Organização Pan-americana da Saúde.

BREILH, J. \& GRANDA, E., 1986. Investigação de Saúdena Sociedade: Guia Pedagógico Sobre um Novo Enfoque do Método Epidemiológico. São Paulo: Instituto de Saúde/ Rio de Janeiro: ABRASCO.

BRONFMAN, M. \&TUIRÁN, R., 1984. La desigualdad ante la muerte: clases sociales y mortalidad en la niñez. Cuadernos Médico-Sociales, 29/30:53-75.

BRONFMAN, M., VICTORA, C., LOMBARDI, C.; FACCHINI, L. A.; BARROS, F. C.; BÉRIA, J. U. \& TEIXEIRA, A. M. B., 1988. Operacionalização do conceito de classe social em estudos epidemiológicos. Revista de SaúdePública, 22:253-65.

DUNNINGHAM, W., 1988. Classes sociais etranstornos mentais. Salvador: Fator Editora Psicanálise.

FORSTER, A. C. \&YAZLLE-ROCHA, J. S., 1991. Hospitalizações e classes sociais. Divulgação em Saúde para Debate, 3:71-77.

\section{Agradecimentos}

Ao Prof. Eduardo Mota, pelo empenho e dedicação na orientação de mestrado, da qual este artigo faz parte, à Profa. Marilisa Berti de Azevedo Barros, pelas sugestões apresentadas no parecer sobre nossa dissertação, e ao Prof. Naomar de Almeida Filho e à Dra. Rosana Aquino, pelo interesse e apoio em todo o desenvolvimento do trabal ho e contribuições à redação final deste artigo.

GUIM ARÃES, A. S. A., 1988. Classes: Ontem e Hoje. Salvador: Centro de Recursos Humanos, Universidade Federal da Bahia. (mimeo.)

LENIN, V. I., 1980. Uma Grande Iniciativa. Obras Escol hidas, Vol. 3, São Paulo. Editora Alfa-Omega.

MONTEIRO, C. A., 1988. Saúde e Nutrição das crianças de São Paulo: Diagnóstico, Contrastes Sociais eTendências. São Paulo: HUCITEC/EDUSP.

POU LANTZAS, N., 1975. As Classes Sociais no Capitalismo de Hoje. Rio de Janeiro: Zahar Editores.

PRZEWORSKY, A., 1989. Capitalismo e Social-Democracia. São Paulo: Companhia das Letras.

SILVA, A. A. M.; BARBIERI, M. A.; BETTIOL, H.; DALB, C. M. R.; MURCÍlIO, G. \& GOMES, U. A., 1991. Saúde perinatal: baixo peso e classe social. Revista de Saúde Pública, 25:87-95.

SOLLA, J. J. S. P., 1990. Algumas considerações sobre a utilização do conceito de "classe social" na investigação epidemiológica. Saúde em Debate, 30:26-31.

SOLLA, J. J. S. P., 1992. Classe Social eSaúde: um Estudo sobre a Utilização deste Conceito na Investigação Epidemiológica. Dissertação de Mestrado: Departamento de Medicina Preventiva, Universidade Federal da Bahia.

SOLLA, J. J. S. P., 1996. Problemas e limites da utilização do conceito de classe social em investigações epidemiológicas: uma revisão crítica da literatura. Cadernos deSaúde Pública, 12(2):207-216

THERBORN, G., 1989. A análise de classe no mundo atual: o marxismo como ciência social. In: História do Marxismo. Vol. 11 (Hobsbawn, E. J., org.), pp. 389-439. Rio de Janeiro: Paz eTerra.

UFBa (Universidade Federal da Bahia), 1986. Projeto: A Morbi-Mortalidade Materno-Infantil em Salvador, Bahia: Características Epidemiológicas, Fatores de Risco e Determinantes Sócio-Econômicos. Salvador: Faculdade de Medicina, Depto. de Medicina Preventiva, Universidade Federal da Bahia.

VICTORA, C. G.; BARROS, F. C. \& VAUGHAN, J. P., 1989. Epidemiologia da Desigualdade: Um Estudo Longitudinal de 6.000 Crianças Brasileiras. 2a ed. São Paulo: HUCITEC.

VICTORA, C. G.; FACCHINI, L. A.; BARROS, F. C. \& LOMBARDI, C., 1990. Pobreza e Saúde: como medir nível sócio-econômico em estudos epidemiológicos de saúde infantil. In: Anais do 1o Congresso Brasileiro de Epidemiologia. Campinas: ABRASCO.

WRIGHT, E. O., 1981. Classe, Crise e Estado. Rio de Janeiro: Zahar.

WRIGHT, E. O., 1985. Classes. London:Verso. 